NASA Technical Memorandum 105716

P.6

\title{
Electromechanical Systems With Transient High Power Response Operating From a Resonant AC Link
}

Linda M. Burrows and Irving G. Hansen

Lewis Research Center

Cleveland, Ohio

Prepared for the

27th Intersociety Energy Conversion Engineering Conference cosponsored by the SAE, ACS, AIAA, ASME, IEEE, AIChE, and ANS San Diego, California, August 3-7, 1992 
Electromechanical Systems with Transient High Power

Response Operating from a Resonant AC Link

\author{
Linda M. Burrows \\ NASA Lewis Research Center \\ Cleveland, Oh. 44135
}

\author{
Irving $\mathrm{G}$. Hansen \\ NASA Lewis Research Center \\ Cleveland, Oh. 44135
}

\begin{abstract}
The combination of an inherently robust asynchronous (induction) electrical machine with the rapid control of energy provided by a high frequency resonant ac link enables the efficient management of higher power levels with greater versatility. This could have a variety of applications from launch vehicles to all-electric a utomobiles. These types of systems utilize a machine which is operated by independent control of both the voltage and frequency. This is made possible by using an indirect field-oriented control method which allows instantaneous torque control in all four operating quadrants. Incorporating the ac link allows the converter in these systems to switch at the zero crossing of every half cycle of the ac waveform. This "zero loss" switching of the link allows rapid energy variations to be achieved without the usualf requency proportional switching loss.

Several field-oriented control systems have been developed by NASA Lewis and General Dynamics Space Systems Division under contract to NASA. This paper will begin with a description of a single motor, electromechanical actuation system and then focus on a conceptual design for an AC electric vehicle. This design will incorporate an induction motor/generator together with a flywheel for peak energy storage. System operation and implications along with the associated circuitry will be addressed. Such a system would greatly improve all-electric vehicle ranges over the Federal Urban Driving Cycle (FUD).
\end{abstract}

\section{Introduction}

There have been many recent advances in the field of electromechanical actuators (EMA's) to provide high response rates and high power levels for thrust vector control (TVC) systems. At NASA Lewis, we are building on resonant converter work developed for us by General Dynamics Space Systems Division (GDSS) [1] and field-oriented control (FOC) research by the University of Wisconsin [2]. GDSS has designed and built $25 \mathrm{hp}$ and $40 \mathrm{hp}$ EMA systems with advanced technologies, such as resonant inverters, pulse-population modulated (PPM) converters, FOC, and induction motors. They are also in the process of developing a $70 \mathrm{hp}$ EMA system capable of meeting the solid rocket booster's thrust vector control needs on a vehicle such as the Space Shuttle. At NASA Lewis, we are investigating advanced EMA systems which also incorporate the above technologies. One particular program involves the use of an advanced flywheel for system load levelling. This paper will describe the overall flywheel system design along with a specific program application.

\section{Background}

The resonant converters used in these advanced EMA systems allow all switching to occur at the zero current crossings, which minimize the losses and stresses on components. These converters operate with high frequencies $(-20 \mathrm{kHz})$, which minimize the size and mass of the control electronics [3].

The pulse-population modulated (PPM) converters allow the independent control of both the voltage and frequency to the induction motor. This in turn makes it simple to vary the speed of the machine [4].

Field-oriented control (FOC) of an induction machine is a technique to control the instantaneous torque in all four operating quadrants, as shown in Figure 1. A simplified induction motor is presented in Figure 2. The magnetic field is displayed as two components, one created by $I_{d}$ and one by $I_{q}$. 
The flux causing direct current component, $I_{d}$, is a function of the voltage to frequency ratio, while the torque causing quadrature current, $I_{q}$, is a function of the flux level and the frequency relative to the actual rotor speed (slip). For the most part, $I_{d}$ is kept constant, which corresponds to a constant flux level. The torque is then controlled solely by the $I_{q}$ component of current. This allows for rapid torque response by instantaneously varying $\mathbf{I}_{\mathbf{q}}$.

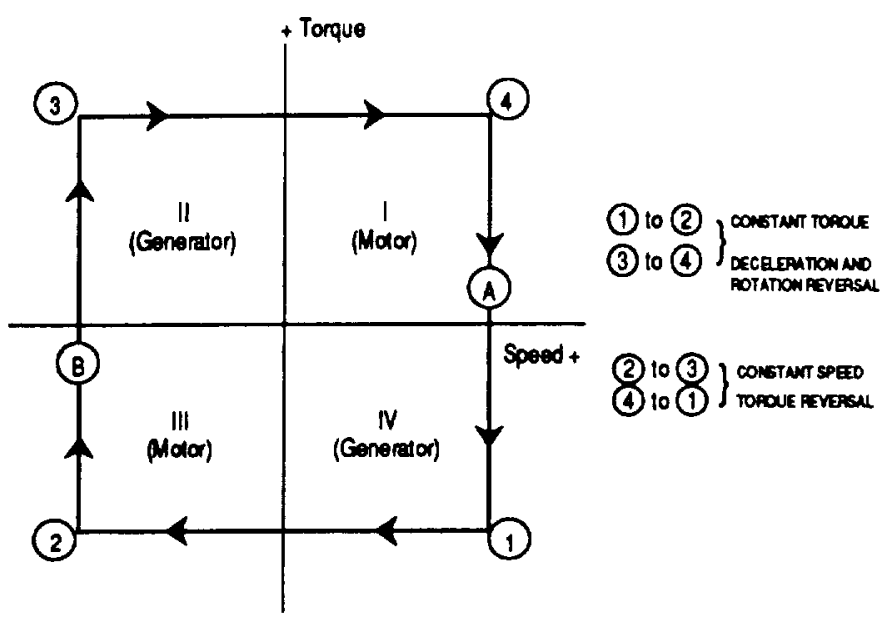

Figure 1-Four Quadrant Trajectory of Machine Operation

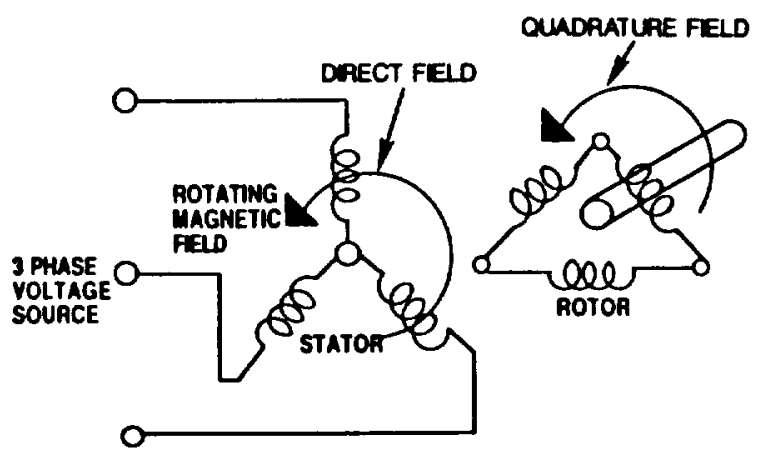

Figure 2-Induction Motor Diagram

The induction machine has always been known for its simple, rugged construction. It is also capable of high temperature operation, high torque/ampere, and fail safe operation for shorted windings due to its lack of residual magnetism. The major disadvantages of the induction motor have been its inability to vary speed rapidly, high inertia, and somewhat lower efficiency. With the techniques described earlier, speed control is no longer an issue. Figure 3 depicts typical induction machine curves using the advanced control techniques and illustrates torque control independent of rotor speed. Power factor and efficiency also remain high over a wide range of torque and speed.

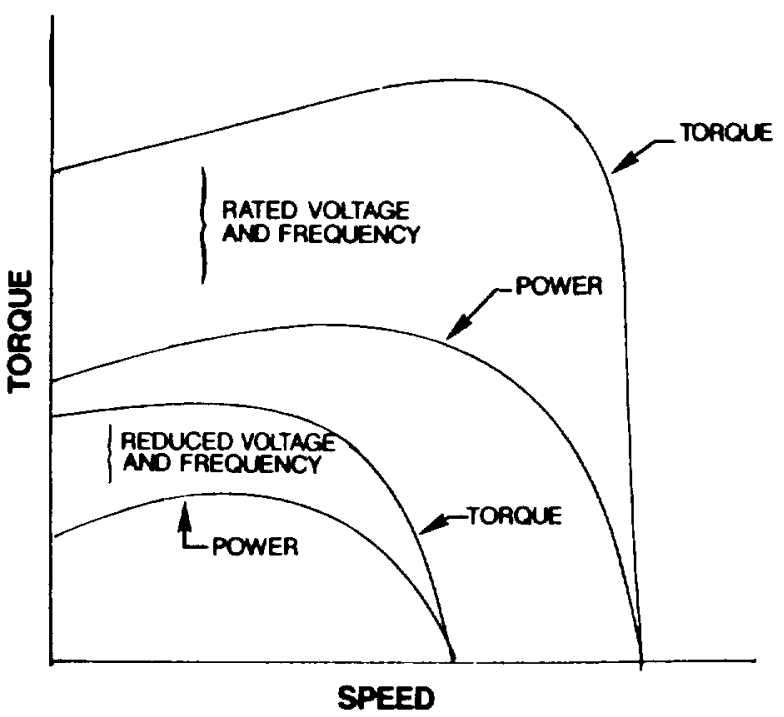

Figure 3-Induction Machine Advanced Control Curves

In order to make an induction machine a viable option in EMA systems, the inertia must be decreased and the efficiency increased. Under contract to NASA Lewis via General Dynamics, the Sundstrand Corporation has developed a low inertia motor capable of $70 \mathrm{hp}$ peaks and weighing only 20 pounds, half of which is the housing alone. Initial tests demonstrated an increase in the machine's efficiency by the varying of flux level to the motor.

The following section describes a specific EMA system using these advanced technologies. The system portrayed will be appropriate for both a hybrid and an all-electric vehicle.

\section{System Description}

One basic problem to be faced in many designs is supplying energy transients in isolated electromechanical systems, such as EMA's or electric vehicles. When electric motors are used to drive widely varying loads, whose peak power requirements are large relative to their average, several interrelated problems arise. If brushless DC motors (PM synchronous) are used, they will be operated over a range of speed in which both their power factor and efficiency are reduced, as shown in Figure 4. As a result, the source experiences high transient load currents that do no useful work. Since the power switching loss, line loss, and part of the load loss are functions of current, or its square, a considerable advantage will be realized if machine power factor and efficiency are maintained and transient source discharges avoided. One brief illustration of this point concerns a typical battery driven electric vehicle. The dis- 
tance realized by steady speed driving is several times that which is obtainable under the transient loading experienced with urban driving. In another example, a rule of thumb used is that for two storage batteries rated for equal energy delivery, one having a 1.5 times higher current rating will weigh twice as much as the other [5].

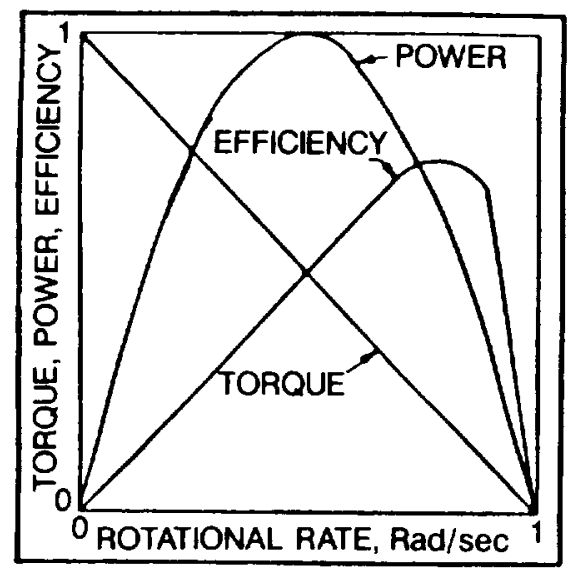

Figure 4-Typical Permanent-Magnet Motor Curves

Several schemes have been proposed to limit the battery discharge by supplying the transient current from an alternate source. Hybrid batteries, capacitor banks, and flywheels are among such proposals. In the case of the flywheel, it could be fabricated as a solid steel wheel having no conductors and driven directly as the rotor in an induction motor/generator [6]. By properly controlling such a simple induction driven flywheel, transient energy storage becomes practical.

Improvement of motor efficiency has been demonstrated by induction motors operating bidirectionally from a high voltage/high frequency link. Independent control of voltage and frequency allow high power factors and low loss to be maintained over a wide duty cycle range. Such systems have been designed for the National Launch System (NLS) at peak power levels up to 70 $h p$ [7]. If the same bi-directional control is performed upon a flywheel driven by an induction motor/generator, the peak power demand will be decoupled from the source.

At NASA Lewis, a joint venture has begun between the Electrical Components and Systems Branch and the Stirling Engine Branch to design a power system for a hybrid vehicle capable of meeting the Federal Urban Driving (FUD) range requirements. The system described here is a modification of that work.

Technologies being researched are high frequency link operation, converters, and flywheels. A block diagram of the overall system is shown in Figure 5.

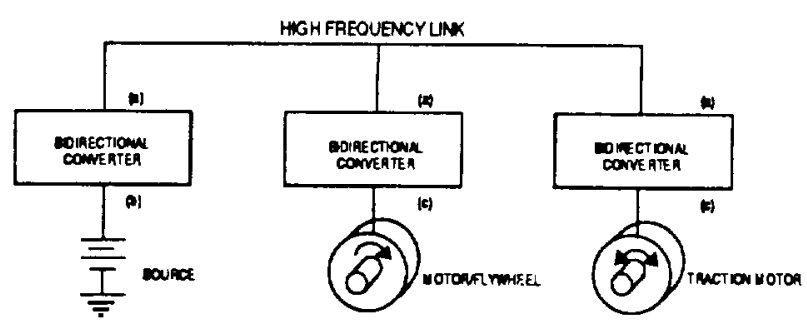

COMYEIIER PORTCHABMCTEBSTCS

(4) HGH FREOUENCY (2) KHEC AC, SWGLE PHUSE CONSTANT VOLTAGE A FFEOUEACY (b) VARIABLE VOL TAGE DC

(c) VAPIABLE VOLTAGE, VARUALE FREOUEACY, 3 PHASE, AC

Figure 5-High Frequency Link Vehicle Power System

If the components shown in figure 5 were sized for the needed requirements, some observations may be made as shown in Table 1.

Table 1-Specifications for a Hybrid Vehicle

$$
\begin{aligned}
& \text { Vehicle weight }=3600 \mathrm{lbs} \\
& \begin{aligned}
\text { Acceleration } & =0-30 \mathrm{mph} \text { in } 4.5 \mathrm{sec} . \\
\text { (Performance specifications) } & 0-60 \mathrm{mph} \text { in } 14 \mathrm{sec} .
\end{aligned} \\
& \text { Continuous climb } 5 \% \text { grade at } 55 \mathrm{mph}
\end{aligned}
$$

The traction motor is sized thermally by the continuous climb requirement of about $30 \mathrm{kw}$. The transient maximum power requirement of the motor is a function of the $0-30 \mathrm{mph}$ acceleration requirement of about $70 \mathrm{kw}$, while the 300 kilojoules of flywheel energy storage required is a function of the 0 to $60 \mathrm{mph}$ acceleration requirement.

Using the flywheel rim directly as the rotor of a solid rotor induction motor, and observing very conservative stress limits in the rotor, a suitable steel flywheel would have less than $200 \mathrm{lbs}$. of active mass. It would also have a power density of $2 \mathrm{KW} / \mathrm{Kg}$ and an energy density of $100 \mathrm{KJ} / \mathrm{Kg}$ [6], which is five times the density available with the latest capacitor development. The required $40 \mathrm{kw}$ bi-directional electronics have demonstrated through other programs full charge/discharge cycle efficiencies of greater than $90 \%$.

The University of Wisconsin, working under a NASA Lewis grant, has simulated this type of system both in software and hardware. Overall, both sets of data show the ability for the flywheel augmented scheme to easily regula te the power bus under transient bi-directional loading. Figure 6 shows the data obtained from the Wisconsin research and demonstrates the ability of the flywheel to supply the peak powers demanded by the load, while allowing the input source to remain at a constant power level. 


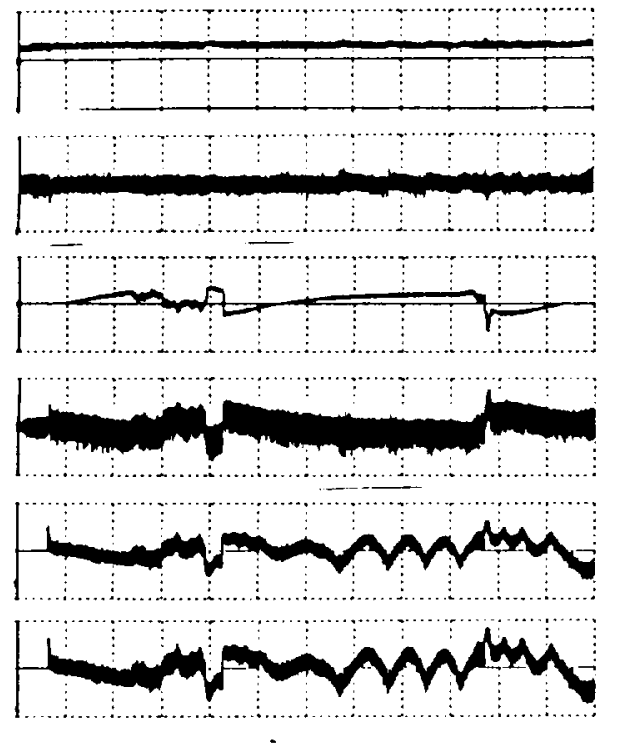

TOTAL SYSTEM (NPUT)

BUS VOLTACE

FLYWHEEL"

POWER OUT

MOTOR POWER

POWER' SENSE

TOROUE COMMAND TO FIYWHEEL"

Figure 6-Flywheel System Data

The data in Figure 6 is taken from a system functionally identical to the vehicle system discussed. The first trace shows that the overall power input is the current delivered to a $20 \mathrm{kHz}$ inverter operated under constant current control, which corresponds to limiting the maximum discharge of the vehicle battery. The second trace shows the link voltage being regulated by controlling the energy into and out of the link.

The third trace shows the energy in and out of the flywheel, which was implemented by using the inertia of an unexcited dynamometer. To generate this data, the motor was driven bi-directionally to control energy on and of $f$ of the bus, as shown in the fourth trace. Successful energy control is demonstrated by the constant amplitude of the link voltage, and the "mirror image" relationship between the third and fourth traces. The fifth and sixth traces are the power sensed to regulate the bus voltage and the torque command to the flywheel converter.

This proposed system shows great promise in providing an alternative for ac all-electric and hybrid vehicles. The technology is available to implement flywheel supplied peak power in an electric vehicle or any isolated electrical actuated system. The test results from the University of Wisconsin provide proof that this is a viable and controllable system.

\section{Conclusion}

Work is continuing at NASA Lewis to study these types of flywheel augmented electromechanical systems. Induction motors, when properly controlled, provide high efficiencies and rugged, low-cost construction. The versatility, efficiency, and controllability of the high frequency distribution, when stiffened by a flywheel, will greatly extend an electric vehicle's urban driving range by limiting the discharge currents of the battery. Based upon the results from the University of Wisconsin, this should prove to be a vital technology in several applications including electric vehicles and airplanes.

\section{References}

1) K. Schreiner, "AC Bidirectional Motor Controller," IECEC, 1988.

2) P.A. Sood, T.A. Lipo, and I.G. Hansen, "A Versatile Power Converter for High Frequency Link Systems," IEEE Trans. on Power Electronics, Oct. 1988.

3) L.M. Burrows, D.S. Zinger, and M.E. Roth, "Field Oriented Control of Induction Motors," 25th IECEC, Aug. 1990, NASA TM 103154.

4) I.G. Hansen, "Four Quadrant Control of Induction Motors," NASA Technology 2000, Nov. 1990.

5) H. Rushing, Lewis Telecon with KSC, April 1992.

6) SatCon Technology Corp., Cambridge Mass., Final Report for Contract NAS3-26232.

7) K.E. Schreiner, and M.E. Roth, "Resonant Mode Controllers for Launch Vehicle Applications," Applied Power Electronics Conference and Exposition, Feb. 1992. 


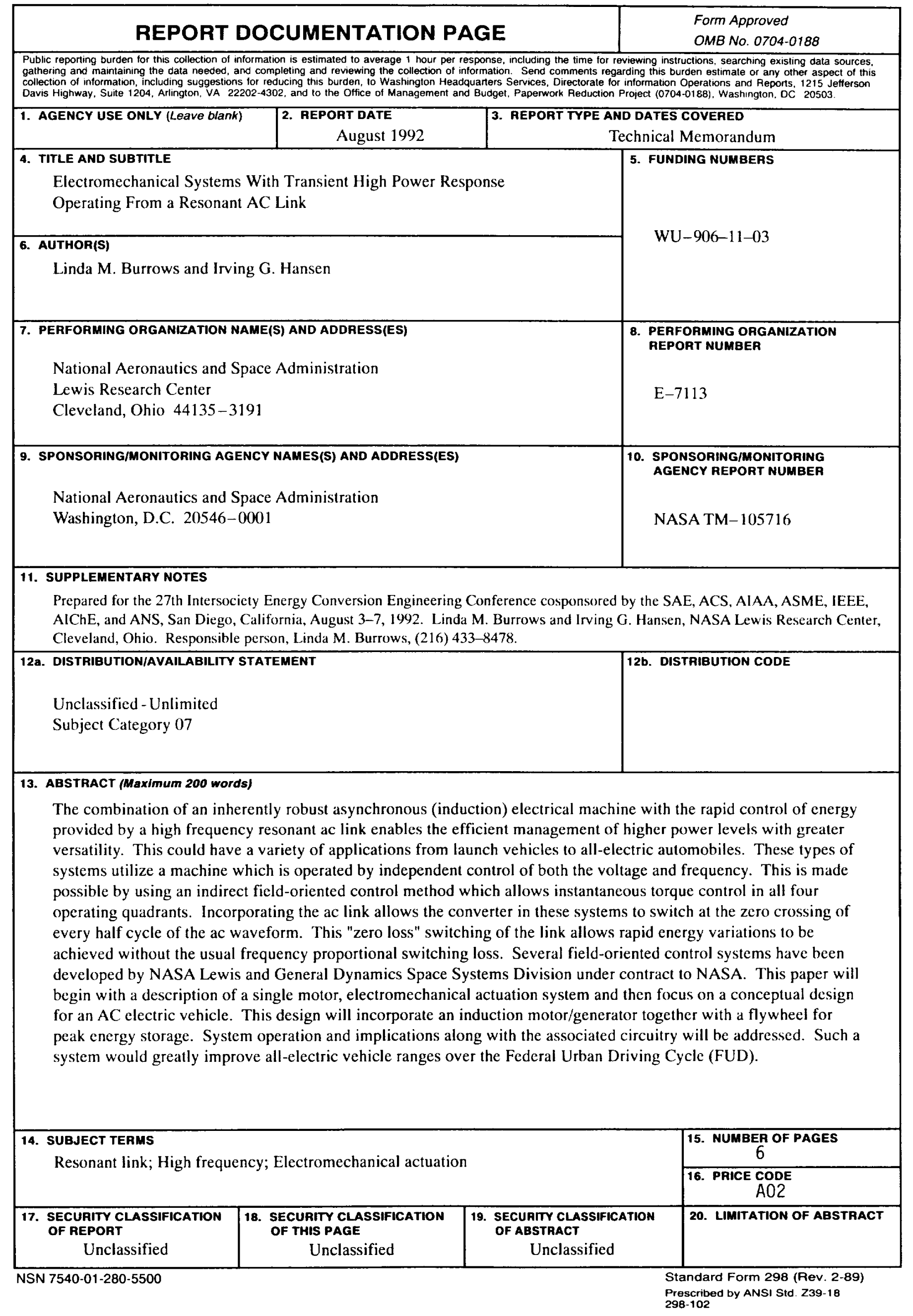

